\title{
Entre o dito e o feito: uma análise preliminar da questão da aflição e do sofrimento nos estudos antropológicos sobre o candomblé
}

| 1 Clarice Moreira Portugal, ${ }^{2}$ Mônica de Oliveira Nunes |

Resumo: O artigo tem por objetivo refletir acerca das abordagens antropológicas do sofrimento nos cultos afro-brasileiros, considerando desde aquelas centradas na dimensão simbólica até as mais afins à fenomenologia e à antropologia simétrica. Para tanto, faz-se inicialmente uma breve exposição acerca dos paradigmas estrutural e simbólico na antropologia, privilegiando a obra de Claude Lévi-Strauss e Clifford Geertz. A seguir, apresenta-se uma discussão concernente à apropriação da teoria fenomenológica pelas ciências sociais e às leituras mais voltadas para a problemática das práticas, enfatizando em nossa leitura autores como Alfred Schütz e Annemarie Mol. Por fim, propõe-se uma nova abordagem teóricometodológica que denominamos cartoetnografia - baseada no conceito de modos de existência desenvolvido por Bruno Latour - como uma espécie de híbrido que nos permitiria, sem negligenciar a dimensão simbólica, explorar o problema da aflição nos cultos afro-brasileiros a partir da fruição das afecçôes, dando visibilidade à construção dessa experiência por meio das práticas que lhe dão forma.

> Palavras-chave: antropologia da saúde; religiões afrobrasileiras; sofrimento; cartografia; etnografia.

\author{
1 Instituto de Saúde Coletiva, \\ Universidade Federal da Bahia \\ Salvador-BA, Brasil. Endereço \\ eletrônico: clariceportugal@ \\ gmail.com \\ 2 Instituto de Saúde Coletiva, \\ Universidade Federal da Bahia. \\ Salvador-BA, Brasil. Endereço \\ eletrônico: monicatorrente11@ \\ gmail.com
}

Recebido em: 16/03/2015 Aprovado em: 28/06/2015 
Neste ensaio queremos refletir sobre possibilidades e limites de abordagens antropológicas centradas na dimensão simbólica e naquelas mais afins à Fenomenologia e à Antropologia simétrica, para pensar a discussão antropológica em torno do sofrimento nos cultos afro-brasileiros. Para tanto, faremos uma breve exposição acerca dos paradigmas estrutural e simbólico, com ênfase na obra de autores como Lévi-Strauss e Geertz, na medida em que suas perspectivas permitem vislumbrar o primado da linguagem e das estruturas simbólicas na compreensão das culturas.

Em seguida, discutiremos a apropriação da teoria fenomenológica pelas ciências sociais e aquelas direcionadas à problemática da práxis, passando por leituras como as de Alfred Schütz, Annemarie Mol e Bruno Latour. Por fim, faremos o esboço de uma nova abordagem teórico-metodológica que nos permita explorar o problema do sofrimento e da aflição nos cultos afro-brasileiros a partir da fruição dos afetos e afecções, dando visibilidade à construção dessa experiência por meio das práticas. Proporemos o que chamaremos aqui de "cartoetnografia", como uma espécie de híbrido, tomando por base os teóricos citados acima.

\section{Da estrutura à interpretação: uma introdução ao problema do simbólico na Antropologia e na compreensão dos rituais}

A denominada "antropologia simbólica" não é uma teoria antropológica, mas uma coleção de propostas que redefinem tanto o objeto como o método antropológico, em oposição declarada ao que se considera como as formas simbólicas dominantes e outorgando uma importância fundamental aos símbolos e significados compartilhados em uma dada cultura.

A antropologia não toma os símbolos como objetos sem as práticas e obras a que toma por "simbólicas". Nesse caso, a primeira operação acerca do simbólico é uma experiência que advém da perplexidade do etnógrafo diante da ambiguidade e dos múltiplos sentidos que irrompem na experiência etnográfica, de onde o antropólogo "presume um dizer, um sentido transmitido" (COSTILLA, 2010, p. 293).

Lévi-Strauss parte do princípio de que as modalidades de pensamento o "selvagem" e o "civilizado" - não diferem em termos de sua natureza. Isso não significa que os signos e os símbolos que os compõem sejam os mesmos, 
mas que sua similitude reside na sua dimensão sintática e na forma pela qual se estabelecem as relações entre eles (AZZAN, 2008). Isso quer dizer que as culturas são diametralmente diferentes umas das outras e não há hierarquização ou maior complexificação entre elas.

Dentre todos os objetos de que pode se ocupar a antropologia, é nos mitos que as condições de entendimento se revelam. Tanto as classificações como os mitos demonstram que os povos sem escrita estão movidos por um desejo de compreender o mundo natural e social em que se desenvolvem. O pensamento mítico, em certo sentido, assemelha-se ao científico exatamente por isso, mas distingue-se dele por seu caráter totalizante (LÉVI-STRAUSS, 1989).

Em "A eficácia simbólica", Lévi-Strauss (1967) aborda a relação entre o mito e o rito como algo para além da realidade objetiva, em princípio potencial, cuja elaboração tem duas fases: a criação de mitos, ordenando o caos; e o mito em ação, o rito, sendo este a dramatização do mito. Mito e rito diriam respeito a modos complementares nos quais a função simbólica se exerce: a separação imposta ao vivido pelo mito deve ser restabelecida para que a vida seja compreendida tal como se apresenta, em um fluxo contínuo e sem falhas. É aqui que a função simbólica deve reconstruir a unidade prejudicada pelo entendimento e aplacar aquilo que emerge como angústia.

Por esse raciocínio, constituem uma linguagem e são por ela constituídos, ou seja, está em jogo aqui algo compartilhado e que se reconstrói por meio de sua encenação ritual. Traçando um paralelismo entre a psicanálise e a medicina ocidental, o autor deixa claro que a terapêutica e a cura encontram-se atreladas ao abismo entre significante e significado. Estando o primeiro situado no âmbito da forma e o segundo no âmbito do conteúdo, o que o faz, portanto, irredutível ao primeiro,

A carga simbólica de tais atos torna-os próprios para constituírem uma linguagem: certamente o médico dialoga com seu doente, não pela palavra, mas por meio de operaçôes concretas. [...] O médico executa as operações e o doente produz seu mito; na cura xamanística, o médico produz o mito e o doente executa as operações. (LÉVI-STRAUSS, 1967, p. 231-232).

Ao nos valermos dessa perspectiva para pensar as relações terapêuticas, podemos dizer que elas se estabelecem em uma espécie de interstício entre o concreto e o abstrato, engendrando uma produção mítica e semiológica permeada por toda uma factualidade de onde se torna possível (e cabível) a construção da cura. 
Se Lévi-Strauss toma a significação como produto das relações entre os termos componentes de um sistema, presumindo a existência de um código regulador dessas relações a ser decifrado, para Geertz a relação entre os termos dá lugar ao termo em si, e o que está em jogo não é a cultura enquanto estrutura, mas enquanto texto. Geertz parte da pressuposição de que é na parte e não no todo que reside o caráter diferenciador para análise, ao passo que, em Lévi-Strauss, é o todo que possibilita a relação entre as partes. Desse modo,

[...] a diferença entre o modelo interpretativo e o estrutural não é, portanto, principalmente formal: tal diferença fundamental está no conteúdo daquilo que os modelos dizem. Por assim dizer, enquanto o modelo estrutural modela seu objeto, o interpretativo informaliza o seu (AZZAN, 1993, p. 21).

O autor em questão contrapõe Geertz a Lévi-Strauss ao afirmar que, se o primeiro trabalha o sentido como manifestação da vida social, o segundo tenta, por meio do método estrutural, captar a "infraestrutura” do processo de significação, como uma espécie de realidade subjacente, a qual, ao mesmo tempo, dá sustentação ao sentido.

De acordo com Geertz, o etnógrafo inscreve discursos sociais. Coloca-os por escrito e, ao fazê-lo, passa a uma relação desse fato que existe em suas inscrições e que pode voltar a ser consultada. Embrenha-se em um terreno onde se misturam e se confundem diversas estruturas conceituais, que ele deve primeiramente apreender e depois apresentar; e isso exige escolhê-las e determinar sua base social e importância (GEERTZ, 2008, p. 7).

Geertz afirma a questão dos sistemas culturais, tais como a religião e a ideologia. Sua definição de símbolo, por seu turno, diz respeito a "qualquer objeto, ato, acontecimento, qualidade ou relação que serve como vínculo a uma concepção - a concepção é o "significado" do símbolo" (GEERTZ, 2008, p. 67-68). O conteúdo veiculado, todavia, acessível publicamente pelos símbolos, não se faz entender unicamente como ideias, mas também como padrões de conduta e modelos de comportamento.

A análise cultural envolveria (ou deveria ser) uma elaboração explanatória acerca dos significados reconhecidamente baseada nas conjecturas do antropólogo. Ao propor uma “abordagem semiótica da cultura”, Geertz (2008, p. 17) traz o mote de acessar o mundo conceitual dos sujeitos de pesquisa e propõe uma análise das formas simbólicas ligada aos acontecimentos da vida comum e cotidiana e aos dilemas existenciais que lhes são inerentes. Ou seja, não se trata de estabelecer 
um idioma peculiar e esvaziado da mundaneidade por meio da interpretação antropológica, mesmo porque se ela

[...] está construindo uma leitura do que acontece, então divorciá-la do que acontece - do que, nessa ocasião ou naquele lugar, pessoas específicas dizem, o que elas fazem, o que é feito a elas, a partir de todo o vasto negócio do mundo - é divorciá-la das suas aplicações e torná-la vazia. (GEERTZ, 2008, p. 13).

Referindo-se às religiōes, Geertz assinala que a fé se sustenta mediante formas simbólicas e construções sociais. O que uma religião é, em seu conteúdo específico, ganha forma nas imagens e metáforas institucionalizadas e oferecidas aos fiéis, de modo a subsidiar sua apreensão da realidade. Ela estabelece disposições poderosas e duradouras por meio de formulação de conceitos que organizam a ordem de uma existência geral.

Em "Do ponto de vista dos nativos" (1997), Geertz mais uma vez coloca como central a questão dos significados e dos símbolos, na medida em que eles permitem, a partir do jogo entre o que cunha como experiência-próxima e experiência-distante, retomar a problemática das perspectivas êmica e ética, realçando as peculiaridades do ponto de vista do nativo e do pesquisador. O antropólogo de modo algum afirma uma em detrimento da outra, mas, ao contrário, salienta que é possível aproximar-se e compreender a subjetividade do outro sem buscar anular a sua própria. Para tanto, ele afirma a primazia de compreender os sistemas simbólicos entendidos enquanto modos de expressão, ou seja, centrando-se naquilo que o nativo traz acerca de si mesmo.

Segundo Azzan (1993), Geertz inspira-se na semiótica e talvez dela tenha recuperado a perspectiva do sentido enquanto necessariamente um sentido-para, de maneira que o mote é compreender aquele para quem o sentido se faz. Ao mesmo tempo, recorre à hermenêutica ao sustentar que a cultura e seus sentidos podem ser lidos, tal como um texto. A teia de significados por ele enunciada residiria em um "complexo jogo de interpretações e contrainterpretações, possíveis porque intérprete e interpretado comungam os mesmos mundos de sentido, que produz tal 'teia"' (p. 16). O sentido é o que permite entender o mundo e a racionalidade é apenas mais um produto desse entendimento, sendo necessariamente derivada do sentido e, logo, uma racionalidade-para.

Diante do exposto, percebemos que a antropologia simbólica se conforma com uma exploração acerca do caráter concreto de nossos instrumentos de comunicação e representação. Além disso, o símbolo não pode ser isolado dos 
contextos em que se exerce enquanto tal, de onde se pode extrair seu aspecto ligado ao mundo vivido e concreto.

No estudo dos processos de tratamento que se dão no contexto de grupos religiosos sobressaem duas questões básicas: os modos de reconstrução da experiência da doença dentro do domínio religioso e as formas pelas quais a experiência religiosa de cura repercute no cotidiano.

Rabelo, Motta e Nunes (2002) ressaltam o papel dos rituais na transformação da experiência da aflição, sobretudo devido ao caráter de rompimento da vida cotidiana e às alterações de atitude e atenção que demandam. Essa suspensão ritualística por certo conjugar-se-ia à reinterpretação dos dramas e aflições cotidianos; mas nesse mesmo texto é problematizada a leitura demasiado intelectualizada da experiência religiosa que a submete à tomada de posse de novos esquemas interpretativos, o que conduziria a mudanças comportamentais. Por isso, coloca-se em questão o problema da ação e da performance, ainda bastante nebulosos no olhar sobre a aflição e sua remissão nos espaços dos cultos afro-brasileiros.

As reverberações das abordagens simbólicas são claras no âmbito dos estudos acerca do sofrimento e da busca por cuidado nos cultos afro-brasileiros. Enquanto Teixeira (1994) privilegia a questão dos dramas sociais vividos pelos koloris - termo yorubá que literalmente significa "sem cabeça” e que serve para designar pessoas que padecem de transtornos mentais -, Nunes (1999) atribui centralidade ao "idioma do candomblé" enquanto possibilidade de ressignificação das experiências de sofrimento de pessoas em sofrimento mental.

Emerge daí uma vastidão de referências que virão subsidiar sua relação com a comunidade, havendo "uma construção progressiva e interativa da pessoa em relação a uma série de divindades e de elementos simbólicos disponíveis no Candomblé” (NUNES, 2007, p. 103). Dá-se, assim, a apreensão de todo um arsenal simbólico, do qual as pessoas podem se valer para expressar, interpretar e significar sua experiência de sofrimento e também a condução de seus projetos terapêuticos.

O “idioma do Candomblé" aparece como um recurso importante para estabelecer laços sociais, mas também na tradução de sua experiência e constituição do mundo, e está articulado ao cuidado à saúde mental por meio da evocação de significantes imbricados no arsenal litúrgico e ritualístico do candomblé. Já os autores de Galinha d'Angola (VOGEL; MELLO; BARROS, 
2001) colocam que a "linguagem dos infortúnios" vem traduzir e orientar o processo de angústia e suspensão da rotina que conduz à chegada ao candomblé e que dá lugar a transformação e reorientação da experiência a partir da iniciação.

Amparado no referencial hermenêutico, Caprara (1998) mostra como no seu campo etnográfico em alguns terreiros de candomblé, o orixá Omolu conectase ao entendimento do adoecer e da cura sedimentado em todo um arcabouço semântico necessário para estabelecer a correta comunicação com a divindade. Em trabalho também tributário da tradição antropológica de análise de narrativas, Rodrigues e Caroso (1999) trazem elementos para pensar a condição de sofredor do curador em cultos afro-brasileiros.

Esses trabalhos são de grande importância e robustos em sua delimitação teórico-conceitual, mas não se propõem a trabalhar com essa questão pelo vértice da experiência. Posteriormente, autores como Gomberg (2008) e Portugal (2014) virão abordar os itinerários terapêuticos dentro do candomblé a partir das illness narratives (KLEINMAN, 1988) e da experiência de adoecimento passível de captura por meio da elaboração narrativa. Esses autores aliam suas pesquisas menos à construção do itinerário terapêutico em termos práticos do que à sua reconstrução narrativa.

É indubitável a importância das narrativas nos estudos antropológicos em torno da aflição; vale ressaltar, porém, que o aspecto experiencial não deve ser negligenciado (CAPRARA, 1998), dada sua primordialidade na compreensão do processo de adoecimento (KLEINMAN, 1988). Diante dessa lacuna, faremos a seguir algumas consideraçôes relativas à retomada da experiência e da prática nas ciências sociais, de modo a tecermos algumas aproximações que podem colaborar para uma abordagem do sofrimento e da experiência de aflição de adeptos de cultos afro-brasileiros.

\section{A aflição atuada e vivida: possibilidades e limites de um olhar voltado para as práticas}

Quando as teorias sociais se voltam para a problemática da prática e da agência - em finais dos anos 70 e início dos anos 80 -, parecia haver certo cansaço em relação às abordagens mais estruturalistas. Dá-se aí o deslocamento de uma perspectiva que, de certa forma, cinde estruturas e sujeitos a outra que coloca em pauta a importância de observar situações e cotidianos. 
Uma significativa contribuição para essas abordagens veio da fenomenologia. Ao traçar uma contundente crítica ao dualismo sujeito-objeto e à suposição de que a verdade primeira sobre as coisas e/ou o mundo viria do intelecto, Husserl (2006) afirma a correlação entre a consciência e aquilo que a ela se apresenta. Seu esforço central foi "voltar às coisas mesmas", no sentido de explorar como as coisas se dão para a consciência. Dessa forma, não faz sentido falar em consciência e objeto como dimensões estanques, mas tratar-se-ia sempre de uma "consciência de" e de um "objeto para", de forma que um não existe sem o outro.

Alfred Schütz (2012), que se vale do arcabouço fenomenológico para construir sua teoria sociológica, compreende que as interpretações sobre o mundo baseiamse em um estoque de experiências prévias, de forma que a atitude natural residiria nesse agir no e sobre o mundo com interesse eminentemente prático, a partir de uma visão do mundo como previamente dado e estável. Segundo ele, o olhar fenomenológico permitiria colocar em questão algumas concepções sobre a relação homem-mundo aparentemente autoevidentes (p. ex. homem como ser social, premência da linguagem e da ordem simbólica, etc.). Além disso, a redução fenomenológica, captada enquanto método, ao romper com a atitude natural, "torna acessível o próprio fluxo da consciência, como um reino que existe em si mesmo, em sua natureza absolutamente singular" (SCHÜTZ, 2012, p. 71) ainda que sempre incompleta, dada a mundaneidade inerente à condição humana.

A herança da fenomenologia para o conhecimento e a pesquisa em ciências sociais, porém, não se resume à obra de Schütz. Csordas (1994), ao compreender que a fenomenologia cultural deve se situar em complementaridade a uma antropologia interpretativa, traz um olhar distinto para os rituais de cura em contextos religiosos. Ele vê que estão em jogo neles uma concepção de pessoa tripartite que envolve corpo, mente e espírito, bem como todo um escopo de atos performativos que empoderam os sujeitos envolvidos. Na experiência corpórea, assim, não só se encontraria o "solo existencial" da cultura e do sagrado (1994, p. 5), mas dela se derivaria toda uma especificidade do efeito da cura religiosa, diretamente ligada à transformação do self que se dá contiguamente a ela.

Ao conceber o conceito de corporeidade (embodiment), Csordas (1990) desloca o corpo da posição de objeto a ser estudado em relação à cultura. Isso não quer dizer que as culturas tenham a mesma estrutura da experiência corporal, 
mas sim que a experiência corporificada é o ponto de partida para a análise da participação humana em um mundo cultural (CSORDAS, 2002).

A corporeidade possuiria dois analisadores fundamentais: o conceito de percepção, na perspectiva de Merleau-Ponty, e de prática, na concepção de Bourdieu. Entre os dois pensadores, é possível estabelecer uma convergência no que diz respeito à importância que conferem à ruptura com uma perspectiva racionalista na compreensão do corpo, respectivamente desenvolvida a partir da noção de corpo próprio e do conceito de habitus. Contudo, se o primeiro privilegiaria o aspecto pré-lógico e singular da experiência no mundo, o segundo destacaria a característica inconsciente da incorporação do social pelos indivíduos.

O primeiro dará o nome de "praktognosia” a uma espécie de conhecimento prático e corporal que não se reduz ao mero automatismo. Remetendo a uma compreensão do mundo por meio do corpo que não passa por representações e tampouco subordina-se a uma "função simbólica” ou “objetivante" (MERLEAUPONTY, 1999, p. 195), diz respeito a uma apreensão não temática da situação. A percepção, assim, seria um processo encarnado desde o começo: os objetos não preexistem a ela, mas ganham existência a partir da intencionalidade que lhes é dirigida e da relação de materialidade que se estabelece entre corpo e objeto. Logo, é pré-objetiva, no sentido de que ela não começa nos objetos; mas não é pré-cultural, sendo precocemente imersa em um mundo de valores e de símbolos e variável histórica e culturalmente.

Sua fenomenologia, portanto, dá outro estatuto ao corpo ao retirá-lo do polo oposto à consciência; consciência esta que seria ela mesma corporificada, ao tempo em que a compreensão se dá através de um “corpo vivido” e habitado por transformações dos modos de vida, das dinâmicas relacionais e de sociabilidade, dos valores morais e econômicos, dos ethos culturais e das ecologias ambientais.

Já para o segundo, o corpo, informado socialmente, é o "princípio gerador e estruturador das práticas e das representações" (ORTIZ, 1983, p. 61), e a consciência a forma do cálculo estratégico articulado a um sistema de potencialidades objetivas, que constituiria o habitus. Para Bourdieu (2008), subjaz a toda ação um horizonte de experiências prévias, de forma que as estratégias não se reduziriam a planos racionais e conscientes, mas envolveriam também uma espécie de "senso de jogo" que só se adquire quando nele se está inserido. Dessa 
1322 forma, o habitus viabiliza a incorporação de estruturas sociais sob a forma de estruturas de disposiçōes. O eu, que compreende de forma prática o espaço, seria um sistema de disposições que ocupa uma posição e toma posição, de onde se apreende o caráter político das disposições corporais. A partir dessa orientação, compreende-se o habitus como

[...] um sistema de disposições duráveis e transponíveis que, integrando todas as expe-
riências passadas, funciona em cada momento como uma matriz de percepções, apre-
ciações e ações e torna possível cumprir tarefas infinitamente diferenciadas, graças à
transferência analógica de esquemas. (BOURDIEU, 2002, p. 261).

Adotando uma perspectiva também muito voltada para a prática, Latour e Mol vêm abordar as diversas associações que possibilitam a existência no mundo das mais diversas entidades. Ambos avançam suas teorizações a partir de uma tomada da realidade enquanto fluida e múltipla, sendo irredutível somente aos signos e significados que a constituem, ganhando força aqui a investigação das práticas.

Mol (2002), em sua ontologia múltipla, vem elaborar o que ela mesma cunha como uma filosofia empírica, propõe um retorno à realidade, tal qual ela é atuada (enacted) em suas dimensões prática, material e associativa. A escolha pelo termo enact visa a enfatizar o fato de que aquilo que se quer investigar - no caso dela, a doença - não pode ser isolado das práticas nos quais é elaborado e/ ou performado. Mol (2002) percebe que a doença não é unívoca, mas elaborase multiplamente. Isso porque, ao ser sempre atualizada na prática, está sempre suscetível a adquirir novos matizes e acaba, de uma forma ou de outra, sendo sempre produto de uma realização que só pode ser compreendida nos seus diversos modus operandi e nas condições de existência a ele subjacentes. Nessa realização, diferentes versões e modos da doença se confrontam e se aproximam, de modo que seria mesmo possível falar em uma coexistência desses, de onde se pode apreender sua "multiplicidade ontológica".

A experiência de tratamento em contextos religiosos traz em si dimensões interpretativa e performática que se constituem mutuamente, a elas sendo subjacente a experiência sensório-corporal que mergulha o participante do ritual em uma diversidade de estímulos que se mesclam em uma situação específica e idiossincrática que ali se constitui e à qual o indivíduo responde.

Nesse sentido, Rabelo, Motta e Nunes (2002) aludem à importância dos processos imaginativos, os quais dariam sustentação à gênese semiológica e experiencial no âmbito dos tratamentos religiosos. Seria, em grande medida, 
nesta atividade criadora que repousaria a possibilidade de uma transformação da experiência. Alinhando-se a Geertz, veem a religião como um subsistema cultural que, nas terapêuticas que empreende, gera e mantém toda uma série de hábitos em seus partícipes, ao mesmo tempo que fornece ao sujeito em aflição um grupo de referência que sustenta os significados e experiências construídos no contexto ritual e reforça as identidades ali construídas.

Para Alves e Rabelo (1998), não se trata de identificar o momento em que a cultura se faz presente na experiência de adoecimento, mas de compreender que o modo de vivenciar a aflição relaciona-se a uma síntese pré-reflexiva e anterior à construção de uma representação acerca da doença pelo sujeito. Essa experiência colocaria o sujeito diante do incomensurável, o que conduziria a um certo modo de se colocar diante da doença. Esse processo, como já foi colocado, não opõe (ou superpõe) o corpo à palavra, ou as práticas às representaçôes, mas envolve a imbricação entre eles. Dito de outro modo, ao tempo em que o projeto adquire seus contornos, pode ser revisto ou transformado, pois os fins constroem-se no engajamento situacional.

Segundo esses autores, somente

nesses termos podemos entender porque a doença, ao romper com o caráter dado ou pressuposto de esferas da vida cotidiana, coloca em questão elementos do estoque daí as dúvidas, incertezas e vacilações que marcam muitas das experiências cotidianas de adoecer e lidar socialmente com a enfermidade. (ALVES; RABELO, 1998, p. 115)

Seguindo pelas trilhas praxiológicas para pensar a aflição ou o sofrimento, deparamo-nos com outro conceito que se mostra bastante frutífero, a saber, o de modos de existência, elaborado por Latour (2013). Recorrendo ao pensamento de Etiénne Souriau - que se preocupava com os diferentes modos de ser e de suas intensidades - Latour concebe a religião, a ciência, o discurso amoroso como modos de existência distintos, com gêneses e atributos específicos que, por se entrecruzarem, podem levar àquilo que o filósofo denomina "erro de categoria", que tem a ver com a tomada das condiçōes de felicidade de um modo de existência pelas de outro.

Isso não significa, porém, que o entrecruzamento entre diferentes modos de existência seja necessariamente problemático, pois a constituição de um dado modo de existência mantém-se também por descontinuidades. Independentemente de qual seja, o modo de existência, dentro da perspectiva latouriana de uma ontologia histórica, precisa ser instaurado, pois é uma versão 
do ser-como-outro (uma lacuna entre descontinuidade e continuidade, diferença e repetição, alteridade e mesmidade) e também possui seu próprio regime de veridicidade, que não pode ser aplicado imediatamente a outro, sem que isso conduza a um erro de categoria.

No tocante ao sofrimento, podemos destacar o que Latour (2013, p. 190) chama de "modo de existência da metamorfose" (MET). Segundo o autor, a metamorfose diria respeito à experiência aterradora da crise e possui diversas nomenclaturas distintas a depender do contexto cultural em questão, por exemplo, a ideia de mau olhado, encosto ou obsessão espiritual. Com respeito a isso, Latour destaca que esse modo de existência ganha visibilidade nos diferentes enquadres terapêuticos, nos quais se torna possível a transformação que muda os signos e conduz a uma espécie de transmutação de si mesmo.

Escapando à negação generalizada da relação com o invisível (e seus seres) tão marcante nos modos de existência estruturantes da Modernidade, os contextos ritualísticos e terapêuticos seriam locais privilegiados para acessar as especificidades da relação com esses seres em seus modos muito particulares de influência, seja por sua presença, seja por sua ausência.

Em alguma medida, o modo de existência da metamorfose pode nos ajudar a dar conta das lacunas deixadas no conceito de "linguagem dos infortúnios" (VOGEL; MELLO; BARROS, 2001), que procura esquadrinhar as agonias e reveses que conduzem uma pessoa à iniciação no candomblé. Sem nos atermos a tal prerrogativa em muito circunscrita às dimensões simbólica e semântica do sofrer, nos alinhamos a Biehl, Good e Kleinman (2007), que enfatizam a importância de tomar a subjetividade como realidade empírica e não só como categoria analítica. Esse esforço implica pensá-la em termos de uma estratégia de existência que envolve aspectos materiais e práticos que demandam olhar para constelações concretas nas quais as pessoas forjam suas vidas.

Reconhece-se, todavia, que já existe uma frente de estudos preocupados com o aspecto vivido da doença mental e sua presentificação, que vem dar margem a suas interpretações e significações. Um bom exemplo relaciona-se ao trabalho de Rabelo (1999), segundo o qual há uma corporificação do sofrimento que atravessa e dá tom à existência do indivíduo que sofre. Este, percebendo-se nessa situação, vê-se diante da necessidade de dar sentido ao que vive, seja como "problema de santo", seja como "problema mental". 
O transe, por esse viés, poderia (em alguns casos) expressar "uma síntese corporal espontânea (pré-reflexiva)" (RABELO, 1999, p. 214), por meio da qual se torna possível não só construir um modo menos duro de lidar com o sofrimento psíquico, mas também um projeto terapêutico no espaço do terreiro de candomblé. A identificação com a religião, dessa forma, faz-se gradualmente, à medida que os corpos dos adeptos se integram a esse novo mundo simultaneamente às negociações que se dão no contexto interacional.

Diante das várias possibilidades com as quais acenamos até aqui, reiteramos que a prática em muito pode contribuir para a exploração do problema do sofrimento e de sua elaboração no contexto dos cultos afro-brasileiros. Os conceitos de modo de existência e de atuação (enact) marcam um olhar distinto acerca das diferentes formas de engajamento e experiência no mundo e, até o momento, não aparecem na literatura concernida com o processo saúde-doença nesse circuito religioso. Ambos colaboram para adentrar os complexos modos por meio dos quais experiências íntimas repercutem na vida cotidiana e compartilhada. Parece possível, inclusive, traçarmos um paralelo entre o modo de existência da metamorfose e os estados de exceção (BIEHL; GOOD; KLEINMAN, 2007) ambos entendidos como momentos de crise que são retroalimentados socialmente e que apenas nos interstícios do exercício compartilhado da alteridade podem alcançar a possibilidade de significação.

Conseguimos observar até aqui como a questão da prática se insere nas ciências sociais e sua repercussão para estudar a aflição e/ou o sofrimento a partir de um contexto sócio-antropológico. Os diversos conceitos aqui apresentados podem ajudar a vislumbrar um sítio para a experiência e as práticas nos processos de aflição que conduzem à busca por ajuda nos cultos afro-brasileiros. De todo modo, parece-nos que a literatura na área ainda carece de um olhar mais aprofundado nessa dimensão, dado o primado da busca pela compreensibilidade e significação dos caminhos existenciais que frequentemente levam aos terreiros, mesmo entre aqueles trabalhos voltados para a experiência de adoecimento.

\section{Ressignificando práticas ou praticando significados do sofrer em yorubá: o esboço de uma cartoetnografia}

Traçado esse panorama, pretendemos neste breve ensaio vislumbrar a possiblidade de uma terceira via entre a experiência e o simbólico. Nossa proposta vai na 
direção de acessar a aflição e o sofrimento entre os partícipes de cultos afrobrasileiros, seja no âmbito da palavra, seja naquele dos afetos e não ditos, mas infligidos nos diferentes modos de existência (LATOUR, 2013). Tal empreitada emerge aqui sob o nome de cartoetnografia.

Trata-se, em certo sentido, de resgatar aqui a noção de cartografia elocubrada por Deleuze e Guattari (1995), que a delineiam como um dos seis princípios do rizoma, a saber: conexão, heterogeneidade, multiplicidade, ruptura a-significante, cartografia e decalcomania. A cartografia teria como norte a premissa da segmentarização espacial e social do vivido (DELEUZE; GUATTARI, 1995a, p.83), cujas linhas se entrelaçam e dão origem aos territórios. Os autores observam que o mapa é aberto, conectável em todas as suas dimensões, desmontável, reversível e suscetível de receber modificações constantemente. Ele pode ser rasgado, revertido, adaptar-se a montagens de qualquer natureza, ser preparado por um indivíduo, um grupo, uma formação social (DELEUZE; GUATTARI, 1995, p. 22).

Neste momento, tomamos aqui a perspectiva afinada àquela de Ingold (2000), que, por uma via distinta, aborda também o problema do mapear. O autor critica a cartografia em seu sentido canônico e que coloca para si como objetivo a construção de uma espécie de carta de navegação unívoca a partir da delimitação de um recorte territorial. Ele vem contrapor essa cartografia ao "mapear" como um descobrir-caminho ou "cartografia do processo", se utilizarmos aqui a expressão de Rundstrom (1993).

Segundo Ingold (2000), ao se imbricar nesse descobrir-caminho, apreendese o mundo por meio da imersão nele. Isso porque o mundo vivido, ou seja, aquele das experiências, encontra-se em contínua criação, que se faz pari passu ao movimento do sujeito no mundo em um processo de alinhamento entre os movimentos e a resposta do mundo a eles. Dessa forma, essa descoberta de um caminho diz respeito a um

[...] avançar de acordo com uma linha de crescimento, num mundo cuja configuração não é exatamente a mesma de um momento para o outro, e cuja configuração futura não pode ser completamente prevista. Caminhos de vida não são, então, predeterminados como rotas a serem seguidas, mas têm que ser continuamente elaborados sob nova forma. E esses caminhos, longe de serem inscritos sobre a superfície de um mundo inanimado, são os próprios fios a partir dos quais o mundo vivo é tecido. (INGOLD, 2000, p. 241-242). 
Cabe dizer, porém, que mesmo sem discordar das perspectivas do etnomapeamento (VIVEIROS DE CASTRO, 2002), muito afim à de Ingold, viemos aqui com uma proposta um tanto distinta. Essa ressalva cabe porque, na perspectiva do etnomapeamento, trata-se de situar as diferenças da perspectiva do cartógrafo à do nativo, observando que este delineia um mundo possível do qual parte, enquanto aquele tem por objetivo propor um desenho de mundo e, assim, traçar uma forma de compreendê-lo e explorá-lo ao fabricar paisagens, povos e caminhos. Cardoso (2013), afinando-se a esse olhar, propõe uma etnocartografia que percebe o ato intercientífico de mapear como um processo rizomático, no qual os atores (humanos ou não) engajam-se perceptiva, performativa e dinamicamente no mundo.

Sem discordar de sua proposta, invertemos os papéis, retirando-os das mãos do pesquisador. Resgatamos, para tanto, a visão de Rolnik (2014) que, baseada em Deleuze e Guattari, concebe a cartografia como um projeto que ganha corpo contiguamente à transformação daquilo que se dispõe a figurar. Por esse raciocínio, enfatiza-se menos o traçar e mais o engajamento na cartografia, dado que ela exige adentrar na realidade na sua dinâmica cotidiana ou, como nos termos dessa autora, de acompanhar a construção e desconstrução de mundos.

A aceitação de outros mundos possíveis, sobretudo em se tratando da relação com o sagrado e do miraculoso diante de situaçôes-limite, como a dor e o sofrimento extremos, mostra-se um instrumento primoroso. Mesmo considerando os riscos, as concepções simétricas auxiliam o cartoetnógrafo a acercar-se da alteridade por uma via potente e criadora, aberta a "outorgar uma credibilidade a essa possibilidade [...], de onde se buscaria uma reconciliação, ou melhor, um entendimento de outros modos nos planos de apreensões conceituais e epistêmicas" (VARELA, 2010, p. 21, tradução do autor).

Com isso, desejamos não somente colocar-nos à disposição e abertos aos sujeitos, cujas histórias, destinos e caminhos delinearão o processo cartográfico, mas antes de tudo reconhecer que nossa trajetória também está em jogo. Entrar nesse processo faz com que o elemento etnográfico - indispensável à dinâmica de uma possibilidade metodológica e conceitual, tal como aqui se esboça - seja mais um elemento nessa espécie de caminhar em conjunto, que exige desvencilharse de protocolos preestabelecidos, ao desenhar um trajeto e simultaneamente percorrê-lo, comprometendo-se com a precisão enquanto "implicação na realidade" (PASSOS; KASTRUP; ESCÓSSIA, 2010, p. 11). 
O campo etnográfico como texto e lugar onde se estuda e não que é estudado, se nos ampararmos novamente em Geertz (2008), remete à permanente abertura a signos e referenciais, que é muito cara à cartoetnografia que aqui propomos. No entanto, o apreço por essa dimensão simbólica não se faz sem o experienciar conjunto, imergindo na massa sem reduzi-la a nossas mãos. Trazendo à baila a perspectiva cartográfica de Kastrup e Passos (2013), ressaltamos a necessidade do duplo movimento: acessar o plano do comum e também construir um mundo comum e heterogêneo, construindo em coletivo a realidade e sendo afetados por ela.

Nossa proposta cartoetnográfica traz em seu bojo também os conceitos já abordados de atuação (MOL, 2002) e de modos de existência (LATOUR, 2013), que nos permitem atentar para os diversos níveis de agência - inclusive aqueles menos nítidos em posturas tidas como apassivadas. Pretendemos seguir os percursos da metamorfose em seus fluxos e contrafluxos, percebendo os hiatos e saltos que permeiam o curso dos afetos e negociações. Evidentemente, não se trata de circunscrever nossa esfera de análise apenas ao modo de existência (MET), mas partimos do pressuposto de que é na conjugação entre os diversos modos de existência - religioso (REL), de reprodução (REP), moral (MOR), entre tantos outros - que se fazem os percursos e se delineiam as trajetórias. A atuação desses modos e seus entrecruzamentos são centrais em nossa empreitada.

Colocando agora em pauta as particularidades do tema de pesquisa que aqui foi posto em posição central e estratégica, é importante frisar alguns aspectos peculiares. Introduzir-nos no terreiro, na residência, no centro de saúde, no Centro de Atenção Psicossocial, no botequim ou mesmo em outros espaços com nossos companheiros da empreitada - chamados por alguns de sujeitos de pesquisa, nativos, entre outros tantos epítetos possíveis - exige cuidados daqueles que se propóem a aventurar-se na cartoetnografia neste campo em particular.

Delírios, momentos de euforia, milagres, solidão e descobertas de toda sorte colocam-se nesse estranho espaço onde o incompreensível e a dor se encontram. Além disso, coloca-se também o problema do estigma que aqui emerge em dupla face - na inserção na religião afro-brasileira, que ainda é bastante passível de discriminação, preconceitos e violências, e no sofrimento causado pelo adoecer. Ao nos inserirmos nessa cartoetnografia, é importante 
lembrar que ela envolve, de certa forma, o experienciar um pouco desse "estar à margem", voluntariamente ou não.

A cartoetnografia trata, em última instância, de acompanhar processos e trava uma ruptura epistemológica no sentido de apostar na horizontalidade entre pesquisador e pesquisado, considerando a interpenetrabilidade de suas posiçōes e a participação de ambos na (des)construção de mundos e modos de existência. Sem perder de vista a regra da prudência (ROLNIK, 2014, p. 69) e a necessidade do pesquisador em reconhecer seus próprios limites, ela permite adentrar os diferentes settings culturais, terapêuticos e existenciais, sem negligenciar a densidade do componente étnico-litúrgico em questão. Dessa forma, permite observar como os diversos modos de existência ensejam-se no devir candomblecista, e como o terreiro - assim como outras esferas de cuidado - também carrega no seu vivenciar a permuta e combinação entre tais modos.

Vale dizer, além disso, que a cartoetnografia é uma proposta teóricometodológica não redutível aos estudos voltados para a aflição em contextos religiosos, mas mostra-se de grande valia nesse nicho por permitir acompanhar os percursos dos atores nos diferentes contextos culturais por onde circulam na elaboração de sua experiência de sofrimento e na busca de sua remissão. Isso porque ela pode vir a permitir uma inserção mais profunda na experiência dos sujeitos. No caso das religiões de matrizes africanas, ela contribui significativamente por permitir tomar o terreiro como um dos vértices dos processos de (des) territorialização em curso, permitindo acompanhar a mutabilidade do processo saúde-doença e dos modos de existência em sua hibridização.

Portanto, o componente etnográfico e interpretativo mais uma vez ganha importância, na medida em que ajuda a sustentar, elaborar, semantizar e traçar relações entre tais experiências, sem que a imersão nesse mundo vivido se torne deletéria ao invés de potente. Ainda assim, o componente cartográfico e perturbador - que traz em si a expressão de toda uma diversidade de significações, afetos, afecçõos e devires que se mesclam nos territórios existenciais, constituindose como "a inteligibilidade da paisagem em seus acidentes, suas mutações" (ROLNIK, 2014, p. 62) - permanece como norteador não só na nomenclatura de nossa proposta de pesquisa, mas, sobretudo, de sua execução, seja no seu fim último, seja no seu próprio trajeto aberto às reorientaçôes, rupturas e construção inerentes a esse caminhar-comum em uma seara tão complexa. ${ }^{1}$ 


\section{Referências}

ALVES, P. C.; RABELO, M. C. M. Intersubjetividade, mundo da vida cotidiana e estoque de conhecimento. In: . (Org.). Antropologia da saúde: traçando identidade e explorando fronteiras. Rio de Janeiro: Fiocruz; Relume Dumará, 1998, p. 107-122.

AZZAN, C. Antropologia e Interpretação. Campinas: Unicamp, 1993. . Estruturalismo e hermenêutica - Lévi-Strauss e seu humanismo sem sujeito: uma reflexão inspirada em Paul Ricoeur. 2008. Disponível em: http://www.fondsricoeur.fr/ uploads/medias/espace_chercheurs/textecolloque2008.pdf. Acesso em: 17 dez. 2014.

BIEHL, J.; GOOD, B.; KLEINMAN, A. Introduction: rethinking subjectivity. In: (Org.). Subjectivity: ethnographic investigations. Berkeley: University of California Press, 2007.

BOURDIEU, P. Esboço de uma teoria da prática. Oeiras: Celta, 2002.

. Razões práticas: sobre a teoria da ação. Campinas: Papirus, 2008.

CAPRARA, A. Médico ferido: Omolu nos labirintos da doença. In: ALVES, P. C.; RABELO, M. C. (Org.). Antropologia da saúde: traçando identidade e explorando fronteiras. Rio de Janeiro: Fiocruz; Relume Dumará, 1998, p. 123-138.

CARDOSO, T. M. Malhas cartográficas: técnicas, conhecimentos e cosmopolítica do ato de mapear territórios indígenas. Anais da Reuniāo de Antropologia da Ciência e Tecnologia, v. 1, n. 1, p. 1-28, 2013. Disponível em: http://www.ige.unicamp.br/ojs/react/article/ view/1219/672. Acesso em: 10 dez. 2014.

COSTILlA, M. La antropología y el sentido. Semántica e interpretación. Tópicos del Seminario, n. 23, p. 291-329, 2010.

CSORDAS, T. J. Embodiment as a Paradigm for Anthropology. Ethos, v. 18, n. 1, p. 5-47, 1990. - The sacred self: a cultural phenomenology of charismatic healing. Berkeley: University of California Press, 1994.

. Body/Meaning/ Healing. New York: Palgrave Macmillan, 2002.

DELEUZE, G.; GUATTARI, F. Mil platôs, v. 1. São Paulo: Ed. 34, 1995. . Mil Platôs: capitalismo e esquizofrenia, v. 3. São Paulo: Ed. 34, 1995 a.

GEERTZ, C. A interpretação das culturas. Rio de Janeiro: Zahar, 2008.

. Do ponto de vista dos nativos: a natureza do entendimento antropológico. In: - O saber local: novos ensaios em antropologia interpretativa. Petrópolis: vozes, 1997, p. 85-107.

GOMBERG, E. Encontros terapêuticos no Terreiro de Candomblé Ilê Axé Opô Oxogum Ladê, Sergipe/Brasil. 2008. 246 f. Tese (Doutorado em Saúde Coletiva) - Instituto de Saúde Coletiva, Universidade Federal da Bahia, Salvador, 2008. 
HUSSERL, E. A Ideia da fenomenologia. Ideias para uma fenomenologia pura e para uma filosofia fenomenológica. Aparecida: Ideias e Letras, 2006.

INGOLD, T. Jornada ao longo de um caminho de vida - mapas, descobridor-caminho e navegação. In: . The perception of the environment: essays livelihood, dwelling and Skill. Londres: Routledge, 2000, p. 219-242.

KASTRUP, V.; PASSOS, E. Cartografar é traçar um plano comum. Fractal, v. 25, n. 2, p. 263-280, 2013.

KLEINMAN, A. The illness narratives - suffering, healing and the human condition. USA: Basic Books, 1988.

LATOUR, B. An inquiry into modes of existence: an Anthropology of the Moderns. Cambridge: Harvard University Press, 2013.

LÉVI-STRAUSS, C. Antropologia estrutural. Rio de Janeiro: Tempo Brasileiro, 1967. O pensamento selvagem. Campinas: Papirus, 1989.

MERLEAU-PONTY, M. Fenomenologia da Percepção. São Paulo: Martins Fontes, 1999.

MOL, A. The body multiple: ontology in medical practice. Durham: Duke University, 2002.

NUNES, M. O. À temps et à contre-temps: les voix des tambours dans l'expérience des psychotiques. 1999. 387 f. Tese (Doutorado em Antropologia) - Département d'Anthropologie, Université de Montréal, Montreal, 1999.

NUNES, M. O. Referentes identificatórios e jogos identitários no candomblé. Ciências Sociais e Religiāo, n. 9, p. 91-116, 2007.

ORTIZ, R. (Org.). A sociologia de Pierre Bourdieu. São Paulo: Ática, 1983.

PASSOS, E.; KASTRUP, V.; ESCÓSSIA, L. Pistas do Método da Cartografia: pesquisaintervenção e produção de subjetividade. Porto Alegre: Sulina, 2010.

PORTUGAL, C. M. Da linguagem dos infortúnios às narrativas de doença: o sofrimento psíquico e a construção de itinerários terapêuticos entre adeptos do candomblé. 2014. 235 f. Dissertação (Mestrado) - Instituto de Comunicação e Informação Científica e Tecnológica em Saúde, Fundação Oswaldo Cruz, Rio de Janeiro, 2014.

RABELO, M. C. M. A experiência de Indivíduos com problema mental: entendendo projetos e sua realização. In: RABELO, M. C. M.; ALVES, P. C.; SOUZA, I. M. (Org.). Experiência de doença e narrativa. Rio de Janeiro: Fiocruz, 1999, p. 205-227.

RABELO, M. C. M.; MOTTA, S. R.; NUNES, J. R. Comparando Experiências de Aflição e Tratamento no Candomblé, Pentecostalismo e Espiritismo. Religiāo \& Sociedade, v. 22, n. 1, p. 93-122, 2002.

RODRIGUES, N.; CAROSO, C. A sina de curar: a palavra de um terapeuta religioso. Horizontes Antropológicos, ano 5, n. 12, p. 183-212, 1999. 
ROLNIK, S. Cartografia sentimental: transformações contemporâneas do desejo. 2 ed. Porto Alegre: Sulina; UFRGS, 2014.

RUNDSTROM, R. A. The role of ethics, mapping, and meaning of place in relations between Indians and Whites in the United States. Carthographica, n.30, p. 21-82, 1993.

SCHUTZ, A. A linha de base de fenomenológica. In: SCHUTZ, A.; WAGNER, T.R.H. (Org.). Sobre fenomenologia e Relaçôes Sociais. Petrópolis: Vozes, 2012, p. 65-83.

TEIXEIRA, M. L. L. A encruzilhada do ser: representações da (lou)cura em terreiros de candomblé. 1994. 296 f. Tese (Doutorado em Antropologia) - Faculdade de Filosofia, Letras e Ciências Humanas, Universidade de São Paulo, São Paulo. 1994.

VIVEIROS DE CASTRO, E. O nativo relativo. Mana, v. 8, n. 1, p. 113-148, 2002.

VOGEL, A.; MELLO, M. A. da S.; BARROS, J. F. P. de. Galinha D’Angola: iniciação e identidade na cultura afro-brasileira. Rio de Janeiro: Pallas, 2001.

VARELA, S. G. Antropología simétrica dentro del ritual de la capoeira Angola em Brasil. Revista de Antropología Iberoamericana, v. 5, n. 1, p. 3-31, 2010.

\section{Nota}

${ }^{1}$ C. M. Portugal participou da concepção, análise e interpretação dos dados e redação do artigo. M. O. Nunes realizou a revisão crítica do conteúdo intelectual do artigo e aprovou a versão final a ser publicada. A pesquisa contou com financiamento do CNPq. 


\section{Abstract}

Between the said and done: a preliminary analysis of the issue of distress and suffering in anthropological studies of candomble

We aim to reflect on the anthropological approach of suffering in the African-Brazilian religions, considering from those focused on the symbolic dimension to those more related to phenomenology and symmetrical anthropology. Therefore, initially we will make a brief statement about the structural and symbolic paradigms in anthropology, focusing on Lévi-Strauss and Clifford Geertz. Then we discuss the appropriation of the phenomenological theory for the social sciences and the perspectives more focused on the problems of practice, emphasizing authors as Alfred Schütz and Annemarie Mol. Finally, we propose a new theoretical and methodological approach named cartoetnografia based on the concept of modes of existence developed by Bruno Latour - as a kind of hybrid that allows us, without neglecting the symbolic dimension, to explore the problem of distress in the African-Brazilian religions from the fruition of affections, giving visibility to the construction of this experience through the practices that shape it.

> Key words: anthropology of health; Afro-Brazilian religions; suffering; cartography; etnography. 